\title{
Increased Expression of FGF-8 Isoforms and FGF Receptors in Human Premalignant Prostatic Intraepithelial Neoplasia Lesions and Prostate Cancer
}

\author{
Eeva M. Valve, Marja T. Nevalainen, Martti J. Nurmi, Matti K. Laato, \\ Paula M. Martikainen, and Pirkko L. Härkönen \\ Department of Anatomy and MediCity Research Laboratory (EMV, MTN, PLH), Institute of Biomedicine, and \\ Department of Pathology (PMM), University of Turku, and Department of Surgery (MJN, MKL), Turku University \\ Hospital, Turku, and Department of Pathology (PMM), Tampere University Hospital, Tampere, Finland
}

\begin{abstract}
SUMMARY: Fibroblast growth factor 8 (FGF-8) is implicated in growth of prostate cancer. Alternative splicing of the human FGF-8 gene potentially allows coding for four protein isoforms ( $a, b$, e, and f). These isoforms differ in their binding to FGF receptors (FGFR) and in their mitogenic and transforming capacity in transfection assays. Here, we used RT-PCR and immunohistochemistry to study the expression of FGF-8 and FGFR isoforms in human prostate cancer $(n=31)$. Nonmalignant prostate specimens from cystoprostatectomies $(n=24)$ were examined as controls. Most prostate cancer samples and some control prostates also contained prostatic intraepithelial neoplasia (PIN) lesions. FGF-8a and e were expressed at significantly higher frequencies in prostate cancer (FGF-8a, 55\%; FGF-8e, 45\%) than in control samples (FGF-8a, 17\%, $p=0.0052$; FGF-8e, $8 \%, p=0.0031)$. On the contrary, FGF-8b was found at an equal frequency in prostate cancer $(55 \%)$ and in control prostates (50\%). Furthermore, a combination of two or three FGF-8 isoforms ( $a, b$, and/or e) was also expressed at a higher frequency in prostate cancer than in control samples $(45 \%$ and $8 \%$, respectively, $p=0.0031)$. Immunohistochemistry with an antibody recognizing all FGF-8 isoforms was more strongly immunoreactive in prostate cancer cells and PIN lesions than in normal-type epithelium. The receptor splicing variants FGFR1IIlc and FGFR2IIlc, which are activated by FGF-8, were found both in prostate cancer and control samples. Interestingly, immunoreactivity for FGFR1 and FGFR2 was much stronger in prostate cancer cells and PIN than in normal epithelium. These results demonstrate, for the first time, that FGF-8 isoforms and their receptors FGFR1IIIc and FGFR2IIIc are expressed at an increased level not only in prostate cancer but also in premalignant PIN lesions. These data suggest that FGF-8 may have an important autocrine role in the development of human prostate cancer. In addition to FGF-8b, the FGF-8 isoforms a and e may be involved in this process. (Lab Invest 2001, 81:815-826).
\end{abstract}

$F$ ibroblast growth factors (FGFs) and their recep$F$ tors have been suggested to be involved in the progression of prostate cancer (reviewed in [Russell et al, 1998] and [Chevalier et al, 1996]). FGF-8 was originally cloned from SC-3 mouse mammary carcinoma cells and classified as an androgen-induced growth factor (Tanaka et al, 1992). FGF-8 has a transforming capacity (Kouhara et al, 1994) and is expressed in both human breast and prostate cancer (Dorkin et al, 1999; Leung et al, 1996; Marsh et al, 1999). In rodents, FGF-8 is widely expressed during embryonal development (Crossley and Martin, 1995; Crossley et al, 1996a, 1996b; Heikinheimo et al, 1994; Lorenzi et al, 1995; MacArthur et al, 1995c; Mahmood et al, 1995; Ohuchi et al, 1994). In adult rodent tissue, FGF-8 has only been detected in testes (MacArthur et

Received January 29, 2001.

This work has been supported by the Academy of Finland, the Finnish Culture Foundation, and the Research and Science Foundation of Farmos. Address reprint requests to: Professor Pirkko L. Härkönen, MediCity Research Laboratory, University of Turku, Tykistökatu 6 A, FIN-20520 Turku, Finland.E-mail:pirkko.harkonen@utu.fi al, 1995c) and in oocytes of ovarian antral follicles (Valve et al, 1997).

Four potential isoforms (a, b, e, and $f)$ of the human FGF-8 gene have been described (Gemel et al, 1996), as well as four FGF receptors (FGFR1 to 4). FGF-8b is the most actively transforming isoform in NIH3T3 cell transfection studies (Ghosh et al, 1996; MacArthur et al, 1995a). This isoform activates the FGFR splicing variants 2Illc, 3IIlc, and FGFR4 whereas FGF-8e activates FGFR3Illc and FGFR4 (Blunt et al, 1997). The FGF-8a isoform did not activate any of the FGFRs in those assays (Blunt et al, 1997). FGFR1Illc was also activated when micromolar concentrations of FGF-8 were used (Kouhara et al, 1994; MacArthur et al, 1995b). The c-type FGFR splicing variants are typically expressed in mesoderm-derived tissues and the b-type receptors in epithelial cells, suggesting that, during normal embryonal development, FGF-8 action is directed from epithelium to mesenchyme in a paracrine manner (MacArthur et al, 1995b). In a rat prostate cancer model, the exon switching from epithelial FGFR2IIIb to FGFR2IIIc was demonstrated to correlate with the process of malignant transformation and tumor progression (Yan et al, 1993). Additionally, FGFR1, which is expressed only in stroma of normal 
rat prostate, was activated in malignant epithelial cells in that model.

The results of previous studies on the role of FGF-8 in human prostate cancer have been conflicting (Dorkin et al, 1999; Leung et al, 1996; Tanaka et al, 1998; Wang et al, 1999). Additionally, the expression of various FGF-8 isoforms in human prostate is not known. Therefore, we analyzed FGF-8 and its isoforms in malignant and nonmalignant human prostate. Samples of prostate cancer from 31 patients and samples of control prostates from 24 cystoprostatectomies were analyzed by reverse transcription polymerase chain reaction (RT-PCR). The localization of FGF-8 was studied by immunohistochemistry in serial sections of 13 prostate cancer and 7 control prostate samples. The intensity of immunoreactivity in cancer cells, prostatic intraepithelial neoplasia (PIN) lesions, and normal-type epithelium was estimated semiquantitatively. Additionally, the expression and localization of the putative FGF-8 receptors were demonstrated and analyzed similarly using RT-PCR and immunohistochemistry.

\section{Results}

\section{Expression of FGF-8 Isoforms in Control Prostate and Prostate Cancer Samples}

We first examined which FGF-8 isoforms were expressed in prostate cancer $(n=31)$ and control prostate $(n=24)$ samples using RT-PCR (Ghosh et al, 1996). The expression of the isoforms a, b, and/or e (or combinations) in representative prostate cancer samples $(n=10)$ and control samples $(n=2)$ are shown in Figure 1. The RT-PCR products were sequenced to confirm the correspondence to different FGF-8 isoforms. The putative human FGF-8f isoform was not detected in any of the samples. The expression of various FGF-8 isoforms in each prostate cancer and nonmalignant control specimen studied is shown in Tables 1 and 2. In prostate cancer specimens, FGF-8b was observed in 17 of 31 cases (55\%), FGF-8a was also found in 17 cases (55\%), and FGF-8e in 14 of 31 cases (45\%) (Tables 1 and 2 and Fig. 1). In control prostates, FGF-8b expression was found in 12 of 24 cases (50\%), whereas FGF-8a expression was found in only 4 cases (17\%) and FGF-8e in only 2 cases (8\%). Interestingly, the FGF isoform $b$, which was previously found to be the most transforming isoform in the in vitro experiments (Ghosh et al, 1996), was not expressed more frequently in prostate cancer than in control prostates. Another interesting finding was that both FGF-8 isoforms a and e were expressed more commonly in prostate cancer (FGF-8a, 17 of 31, 55\%; and FGF-8e, 14 of $31,45 \%$ ), than in control samples (FGF-8a, 4 of 24, 17\%; and FGF-8e, 2 of 24, 8\%; Fisher's exact test $p=0.0052, p=0.0031$, respectively) (Tables 1 and 2 and Fig. 2). Additionally, different combinations of isoforms such as $a+b, a+e$, or $a+b+e$ were found more frequently in prostate cancer than in controls (14 of 31 cases, $45 \%$ versus 2 of 24 cases, $8 \%$; Fisher's exact test $p=0.0031$ ). There was no obvious correlation between the expression of different isoforms and the grade of prostate cancer (Tables 1 and 2).

\section{FGF-8 Immunohistochemistry}

The localization and expression level of FGF-8 protein was studied using a polyclonal goat antibody to FGF-8, which recognizes all FGF-8 isoforms. FGF-8 immunoreactivity was analyzed in sections of randomly selected specimens from 7 cystoprostatectomies (controls) and from 13 prostate cancers (Tables 3 and 4), and the intensity of immunoreactivity was separately studied and classified by two researchers (Tables 3 and 4). FGF-8 immunoreactivity was localized to the cytoplasm of epithelial cells in both PIN lesions (Fig. 3, B and E) and in prostate cancer (Fig. 3, $\mathrm{C}$ and F). Stromal immunoreactivity was generally absent or very weak.

Immunoreactivity was absent or weak in normal epithelium of control prostates (Fig. 3, A and D, and white arrow in B, and Table 3) or in normal-type epithelium of prostate tissue surrounding areas of
CA
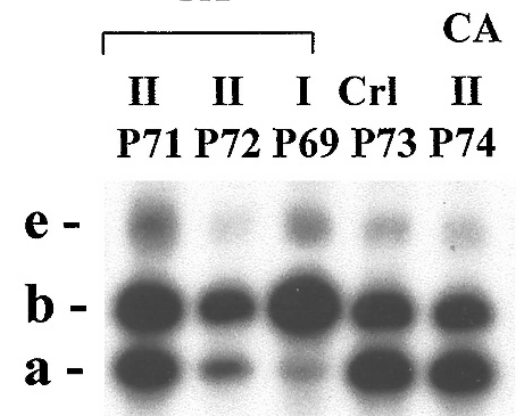

CA

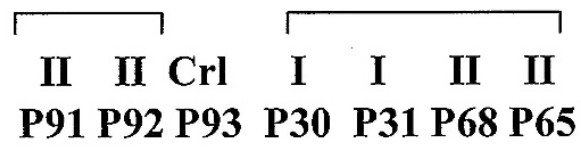

Figure 1.

Southern hybridization of the RT-PCR products of FGF-8 isoforms in prostate cancer $(C A)$ and control prostates (Crn). Total RNA from prostate cancer and control prostate tissue specimens were examined by RT-PCR. The primers were chosen to differentiate the FGF-8 isoforms according to the sizes of the RT-PCR products (Ghosh et al, 1996) (a, 332 bp; b, 366 bp; and e, 420 bp). Examples of RT-PCR from representative prostate cancer specimens from 10 patients and control specimens from 2 patients are shown. FGF-8 isoforms $a, b$, and e were expressed in both prostate cancer and control prostate, whereas no expression of the FGF-8f isoform was detected. 
Table 1. FGF-8 Isoforms in Prostate Cancers

\begin{tabular}{|c|c|c|c|c|c|c|}
\hline $\begin{array}{l}\text { Prostate } \\
\text { cancer }\end{array}$ & $\begin{array}{l}\text { Grade } \\
(\text { WHO) }\end{array}$ & Gleason & FGF-8a & FGF-8b & FGF-8e & $\begin{array}{c}\text { No } \\
\text { isoform }\end{array}$ \\
\hline P9 & I & $3+2$ & & & $x$ & \\
\hline P30 & I & $2+4$ & & $x$ & & \\
\hline P31 & I & $2+3$ & & $x$ & & \\
\hline P49 & I & $2+2$ & & $x$ & & \\
\hline P61 & I & $1+1$ & $x$ & $x$ & & \\
\hline P69 & I & $2+4$ & $x$ & $x$ & $x$ & \\
\hline P109 & I & $2+2$ & & & & $x$ \\
\hline P12 & II & $3+4$ & $x$ & & & \\
\hline P36 & II & $3+4$ & $x$ & & $x$ & \\
\hline P42 & II & $4+3$ & $x$ & & & \\
\hline P43 & II & $4+3$ & & & & $x$ \\
\hline P51 & II & $3+3$ & $x$ & & & \\
\hline P54 & II & $3+5$ & $x$ & & $x$ & \\
\hline P58 & II & $3+4$ & $x$ & $x$ & & \\
\hline P65 & II & $3+4$ & $x$ & $x$ & & \\
\hline P66 & II & $3+3$ & $x$ & $x$ & & \\
\hline P67 & II & $3+4$ & $x$ & $x$ & & \\
\hline P68 & II & $3+3$ & $x$ & $x$ & & \\
\hline P70 & II & $4+3$ & $x$ & $x$ & $x$ & \\
\hline P71 & II & $3+4$ & $x$ & $x$ & $x$ & \\
\hline P72 & II & $2+3$ & $x$ & $x$ & $x$ & \\
\hline P74 & II & $3+2$ & $x$ & $x$ & $x$ & \\
\hline P88 & II & $3+3$ & & & $x$ & \\
\hline P90 & II & $3+3$ & & & $x$ & \\
\hline P91 & II & $3+3$ & & & $x$ & \\
\hline P92 & II & $3+4$ & & & $x$ & \\
\hline P103 & III & $5+4$ & $x$ & $x$ & $x$ & \\
\hline P6 & III & $5+5$ & & & $x$ & \\
\hline P7 & III & $4+5$ & & $x$ & & \\
\hline P8 & III & $4+4$ & & $x$ & & \\
\hline P46 & III & $3+5$ & & & & $x$ \\
\hline$\Sigma 31$ & & & $17(55 \%)$ & $17(55 \%)$ & $14(45 \%)$ & $3(10 \%)$ \\
\hline
\end{tabular}

prostate cancer in carcinoma specimens (Fig. 3C and Table 4). In most PIN lesions found in control prostate (Table 3) or in prostate cancer samples (Table 4), FGF-8 immunoreactivity was clearly detectable or strong. PIN lesions were found in 5 of 7 control prostates and in 7 of 13 prostate cancers studied by immunohistochemistry. Immunoreactivity of PIN lesions for FGF-8 was not found in only one control prostate (P25) (Table 3). In prostate carcinoma samples, cancer cells were mostly moderately or strongly immunoreactive (Fig. 3, C and F). There was, however, a wide variation, ranging from not detectable to strong immunoreactivity of cancer cells within some prostate specimens (Tables 3 and 4). No obvious correlation between the FGF-8 level and the histologic grading of prostatic carcinoma could be detected (Tables 3 and 4).

\section{FGF-8 Receptor Expression in Prostate Cancer and Nonmalignant Prostate}

In vitro experiments indicate that FGF-8 preferentially activates the FGFR isoforms FGFR2IIIc, FGFR3IIIc, and FGFR4 (Blunt et al, 1997). FGFR1Illc is also activated when the concentration of FGF-8 is high (in the micromolar range) (Kouhara et al, 1994; MacArthur et al, 1995b). We used RT-PCR to investigate which of these FGFRs were expressed in control prostates and prostate cancer specimens. Figure 4 shows that FGFR1IIlc and FGFR2IIIc were expressed in both control prostates and prostate cancer specimens. Low levels of FGFR3IIlc expression were found in some prostate cancer samples using increased cycles of RT-PCR. FGFR4 was not detected by RT-PCR. FGFR2IIlb expression was also detected, but at a lower level than FGFR1IIIc or FGFR2IIIc. MCF-7 cells were used as a positive control for FGFR (Johnson et al, 1998).

\section{Immunoreactivity and Localization of FGFR1 and FGFR2}

The localizations and levels of FGFR1 and FGFR2 proteins in control and prostate cancer tissues were investigated by immunohistochemistry in most of the samples examined for FGF-8 immunoreactivity (Fig. 5 and Tables 3 and 4). Both receptor proteins were 
Table 2. FGF-8 Isoforms in Prostates from Cystoprostatectomies

\begin{tabular}{|c|c|c|c|c|}
\hline $\begin{array}{l}\text { Prostates from } \\
\text { cystoprostatectomies }\end{array}$ & FGF-8a & FGF-8b & FGF-8e & No isoform \\
\hline P3 & & $x$ & & \\
\hline P25 & & $x$ & & \\
\hline P26 & & $x$ & & \\
\hline P29 & & $x$ & & \\
\hline P33 & & $x$ & & \\
\hline P34 & & & & $x$ \\
\hline P37 & & & & $x$ \\
\hline P40 & & $x$ & & \\
\hline P41 & & & & $x$ \\
\hline P44 & $x$ & & & \\
\hline P45 & $x$ & & & \\
\hline P63 & $x$ & $x$ & & \\
\hline P73 & $x$ & $x$ & $x$ & \\
\hline P93 & & & $x$ & \\
\hline P99 & & & & $x$ \\
\hline P100 & & & & $x$ \\
\hline P101 & & $x$ & & \\
\hline P102 & & & & $x$ \\
\hline P104 & & & & $x$ \\
\hline P105 & & $x$ & & \\
\hline P106 & & $x$ & & \\
\hline P107 & & $x$ & & \\
\hline P108 & & & & $x$ \\
\hline P110 & & & & $x$ \\
\hline$\Sigma 24$ & $4(17 \%)$ & $12(50 \%)$ & $2(8 \%)$ & $9(37 \%)$ \\
\hline
\end{tabular}

FGF-8 isoforms

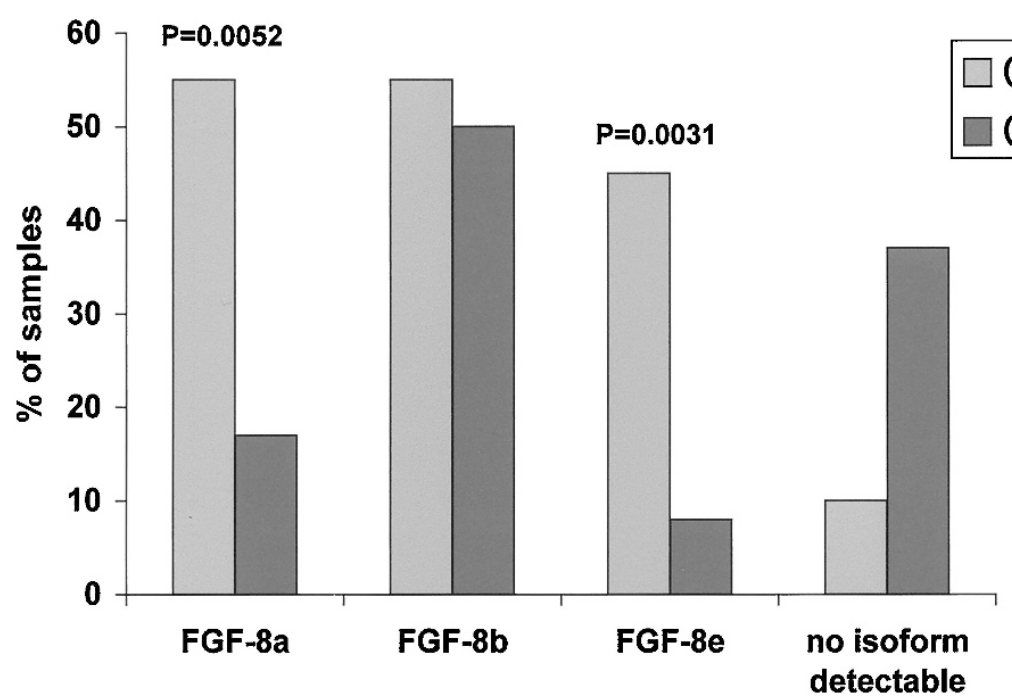

Figure 2.

Relative distribution of FGF-8 isoforms in malignant $(C A)$ and control human prostate. FGF-8 isoforms expressed in 31 prostate carcinoma and 24 control samples (listed in Table 1) were analyzed by RT-PCR. The columns show the percentage of samples expressing FGF-8 a, b, or e and the percentage of samples in which no isoforms were detected.

mainly localized to the membranes of epithelial or cancer cells (Fig. 5). Strong immunoreactivity of basal epithelial cells and faint stromal immunoreactivity were also detected with the antibody to FGFR1.
Intensity of immunoreactivity for FGFR1 and FGFR2 in various regions of control prostate and prostate cancer specimens was estimated as for FGF-8 immunoreactivity (Tables 3 and 4). The immunoreactivity for 
Table 3. Summary of the Results of Immunohistochemical Stainings for FGF-8 and FGFR1 and FGFR2 in Prostates from Cystoprostatectomies

\begin{tabular}{|c|c|c|c|c|c|c|}
\hline \multirow{2}{*}{$\begin{array}{c}\text { Prostates from } \\
\text { cystoprostatectomies }\end{array}$} & \multicolumn{2}{|c|}{ FGF-8 } & \multicolumn{2}{|c|}{ FGFR1 } & \multicolumn{2}{|c|}{ FGFR2 } \\
\hline & Normal & PIN & Normal & PIN & Normal & PIN \\
\hline P25 & 0 & 0 & $0 /+$ & ++ & $0 /+$ & ++ \\
\hline P26 & $0 /+$ & $+/++$ & $0 /+$ & ++ & $0 /+$ & ++ \\
\hline P40 & $0 /+$ & $+/++$ & ++ & ++ & + & $+/++$ \\
\hline P44 & $0 /+$ & - & ++ & - & + & - \\
\hline P45 & 0 & - & $0 /+$ & - & $0 /+$ & - \\
\hline P63 & 0 & + & $0 /+$ & $+/++$ & $0 /+$ & $+/++$ \\
\hline P93 & $0 /+$ & + & $+/++$ & ++ & $0 /+$ & + \\
\hline
\end{tabular}

PIN, prostatic intraepithelial neoplasia; -, no PIN lesions in the sample.

Intensity of immunoreactivity: 0 , none; + , weak, ++ , moderate; +++ , strong; $0 /+, 0 /++, 0 /+++,+/++,+/+++,++/+++$ : heterogenous distribution of immunoreactivity.

both FGFR1 (Fig. 5, A, B, C, and H) and FGFR2 (Fig. 5, $\mathrm{D}, \mathrm{E}$, and $\mathrm{F}$ ) was much stronger in prostate cancer cells (Fig. 5, C and F) and in PIN lesions (Fig. 5, B, E, and $\mathrm{H}$ ) than in normal-type epithelium (Fig. 5, A and D, and white arrows in $\mathrm{B}$ and $\mathrm{E})$. However, similar to the FGF-8 expression, there was no clear correlation between FGFR1 or FGFR2 protein expression and the histologic grade of the prostate cancer. Tables 3 and 4 shows a summary of the immunohistochemistry results for FGF-8, FGFR1, and FGFR2.

\section{Discussion}

Our present work is the first demonstration of increased expression of FGF-8 and its receptors in premalignant PIN lesions. The intensity of immunoreactivity was comparable to that found in prostate cancer samples and clearly increased compared with the normal-type prostate epithelium. We also demonstrated an increased heterogeneity in the expression pattern of the mRNAs for different FGF-8 isoforms in prostate cancer.

Our finding of increased immunoreactivity of FGF-8 in prostate cancer is in agreement with previous reports (Dorkin et al, 1999; Leung et al, 1996; Tanaka et al, 1998). Interestingly, the expression of FGF-8 was also clearly increased in PIN lesions, which are commonly found near cancer but also occur in benign prostates. Our finding adds an important new facet to the possible role of FGF-8 in prostate cancer, and suggests that FGF-8 might be important in early phases of development of malignant changes in prostate epithelium. The expression of FGF-8 in normal prostate epithelium is not known, but our immunohistochemical analyses suggested that expression outside of the PIN lesions would be very low. It is probable, however, that FGF-8 stimulates proliferation of prostatic epithelial cells. Increased expression would thus facilitate the occurrence of malignant transformations of prostate epithelium and the development of PIN lesions, which are thought to be precursors of prostate cancer (Bostwick, 1995). A recent report of increased expression of another member of the FGF family, FGF-6, in PIN lesions would probably also contribute to this process (Ropiquet et al, 2000).

FGF-8 isoforms result from alternative splicing of the FGF-8 gene. In vitro transfection experiments with $\mathrm{NIH} 3 \mathrm{~T} 3$ cells found that FGF-8b is the most transforming mouse (MacArthur et al, 1995a) and human (Ghosh et al, 1996) FGF-8 isoform. FGF-8b was also expressed in the prostate cancer cell lines ALVA-31, DU145, LNCap, and PC-3 (Ghosh et al, 1996). However, in our RT-PCR study, FGF-8b was expressed in both control prostate and prostate cancer specimens. This may be explained by the fact that control prostates were obtained from cystoprostatectomies or that the patients were, on average, as old as the prostate cancer patients and the occurrence of PIN lesions in this age group is high. Thus, although the control samples were normal for the age, and the histologic specimens were nonmalignant according to the histopathologic criteria, several of these prostates contained premalignant PIN changes. Because our immunohistochemistry clearly showed that PIN lesions generally expressed FGF-8, whereas areas of normal epithelium did not, it is probable that the FGF-8b mRNA in RT-PCR of control prostates was mainly derived from these PIN lesions. However, the incidence of at least subclinical benign prostatic hyperplasia in this age group is high. Thus, the regulation of prostatic epithelium and FGF-8 expression may be different from totally normal tissue. In future studies, the expression of FGF-8 in totally normal epithelium compared with benign prostatic hyperplasia or PIN could be analyzed by studying prostates from a younger age group, in which the probability of PIN lesions or benign prostatic hyperplasia is low, or by using microdissected areas of normal and PIN acini for RT-PCR studies.

In our study, FGF-8 isoforms a and e were expressed in a significantly higher proportion of prostate cancers than in control samples. The previous experiments of Ghosh et al (1996) demonstrated that although FGF-8b was the most effectively transforming isoform, the FGF-8 isoforms a and e were also moderately tumorigenic when transfected to $\mathrm{NIH} 3 \mathrm{~T} 3$ cells and injected into the anterior chambers of the eyes of nude mice. Thus it is possible that FGF- 8 a and e isoforms have a specific role in prostate cancer. 
Table 4. Summary of the Results of Immunohistochemical Stainings for FGF-8 and FGFR1 and FGFR2 in Prostate Cancer

\begin{tabular}{|c|c|c|c|c|c|}
\hline $\begin{array}{l}\text { Prostate } \\
\text { cancer }\end{array}$ & $\begin{array}{c}\text { Grade } \\
(\text { WHO) }\end{array}$ & $\begin{array}{c}\text { Gleason } \\
\text { grade }\end{array}$ & FGF-8 & FGFR1 & FGFR2 \\
\hline \multirow[t]{2}{*}{ P9 } & 1 & $3+2$ & $0 /+$ & +++ & $\mathrm{N} / \mathrm{A}$ \\
\hline & PIN & & $++/+++$ & +++ & N/A \\
\hline \multirow[t]{2}{*}{ P31 } & 1 & $2+3$ & $0 /+$ & ++ & N/A \\
\hline & PIN & & ++ & ++ & $\mathrm{N} / \mathrm{A}$ \\
\hline \multirow[t]{2}{*}{ P69 } & 1 & $2+4$ & $0 /++$ & $\mathrm{N} / \mathrm{A}$ & N/A \\
\hline & PIN & & ++ & $\mathrm{N} / \mathrm{A}$ & $\mathrm{N} / \mathrm{A}$ \\
\hline P54 & II & $3+5$ & $+/++$ & ++ & N/A \\
\hline P65 & II & $3+4$ & + & $\mathrm{N} / \mathrm{A}$ & $\mathrm{N} / \mathrm{A}$ \\
\hline P68 & II & $3+3$ & +++ & $\mathrm{N} / \mathrm{A}$ & N/A \\
\hline P70 & II & $4+3$ & $++/+++$ & ++ & + \\
\hline \multirow[t]{2}{*}{ P88 } & II & $3+3$ & + & ++ & + \\
\hline & PIN & & $+1++$ & ++ & + \\
\hline \multirow[t]{3}{*}{ P90 } & ॥ & $3+3$ & $0 /+++$ & $++/+++$ & $+/++$ \\
\hline & PIN & & $0 /++$ & $++/+++$ & $+/++$ \\
\hline & Normal & & $0 /+$ & 0 & 0 \\
\hline \multirow[t]{3}{*}{ P91 } & II & $3+4$ & ++ & $0 /+++$ & $0 /++$ \\
\hline & PIN & & $+/++$ & $0 /+++$ & $0 /++$ \\
\hline & Normal & & $0 /+$ & 0 & 0 \\
\hline \multirow[t]{3}{*}{ P92 } & II & $3+4$ & $0 /+$ & $+/+++$ & $0 /++$ \\
\hline & PIN & & $+/++$ & + & $0 /++$ \\
\hline & Normal & & $0 /+$ & 0 & 0 \\
\hline P8 & III & $4+4$ & + & ++ & ++ \\
\hline P46 & III & $3+5$ & ++ & $++/+++$ & ++ \\
\hline
\end{tabular}

$\mathrm{N} / \mathrm{A}$, not analyzed.

Intensity of immunoreactivity: 0 , none; + , weak; ++ , moderate; +++ , strong; $0 /+, 0 /++, 0 /+++,+/++,+/+++,++/+++$ : heterogenous distribution of immunoreactivity.

Another possibility is that the increased level or increased expression of several isoforms together in prostate cancer cells reflects progression of genetic heterogeneity and instability.

The increased expression of FGF-8 in PIN lesions and prostate cancer cells was generally associated with increased immunoreactivity of FGFRs 1 and 2 in the corresponding areas. This finding supports the possibility that FGF-8 acts as an autocrine factor in prostate epithelium. Our RT-PCR of various splicing variants of the FGFRs indicated that FGFR1IIIc and FGFR2IIIc were the major FGFR mRNA forms in both control prostates and in prostate cancer. Low levels of FGFR3IIlc were, however, found in some prostate cancer samples when more sensitive RT-PCR conditions and increased number of PCR cycles were used (data not shown). Expression of FGFR2IIlb was also detected but, again, the level was low. Our results are consistent with the RT-PCR study of Leung et al (1996), that reported that FGFR2Illc transcripts are expressed in resected prostate cancer tissues. Furthermore, overexpression of both FGFR1 and FGFR2 has been demonstrated in human prostate cancer (Giri et al, 1999). We did not detect expression of FGFR4 in any of our prostate samples. Very recently, however, Ropiquet et al (2000) were able to detect FGFR4 in the normal peripheral zone of prostate tissue and in the prostate cancer cell lines DU145, PC3, and LNCaP using RT-PCR. They noted, however, that the level of expression was relatively low. Our results suggest that
FGFR1 and FGFR2 are the most abundant FGFR forms in human prostate tissue.

FGFR2IIIb mRNA was expressed at a lower level than FGFR1IIIc and FGFR2IIlc mRNAs in prostate cancer samples. This finding is interesting because the b-type receptor splicing form is the major FGFR in various epithelial compartments during murine embryonal development (MacArthur et al, 1995b), whereas there was a gradual loss of the FGFR2IIlb isoform and acquisition of the FGFR2IIlc isoform in a rat model of prostate cancer progression from an androgensensitive, well differentiated tumor to an androgeninsensitive, poorly differentiated tumor (Yan et al, 1992, 1993). In human prostate cancer cell lines and xenograft models, expression of FGFR2IIlb is associated with a more differentiated phenotype than FGFR2IIIc, with an androgen-independent and less differentiated phenotype (Carstens et al, 1997). It will be important to clarify the functional role of various FGF-8 isoforms and FGFR splicing variants in the malignant transformation of prostate epithelial cells.

We report an induction of FGF-8 protein expression and a clear increase in the level of expression of FGFR1 and FGFR2 in PIN and prostate cancer cells compared with normal-type epithelium. Unlike Leung et al (1996) and Dorkin et al (1999), we did not find any obvious correlation between the histologic grade (Gleason or World Health Organization [WHO] classification) of prostate cancer and the level of FGF-8 expression in individual prostate cancer samples. 




Figure 3.

Immunohistochemistry of FGF-8 (A to F) in control prostates and prostate cancer specimens, both containing prostatic intraepithelial neoplasia (PIN) lesions. Immunoreactivities of the control specimen P26 (A, D, B, E) and grade II prostate cancer P92 (C, F) are shown. Positive FGF-8 immunoreactivity was found in the PIN lesions (black arrows in B and $\mathrm{E}$ ) and in prostate cancer cells ( $\mathrm{C}$ and $\mathrm{F})$, but not in normal areas (A, D, and white arrow in B). A control section (P26) with normal goat IgG substituted for the primary $(G)$ was negative. Bar, $100 \mu \mathrm{m}$.

There was also no obvious correlation between the expression of different isoforms and the grade of prostate cancer. It is possible that for FGF-8-isoform expression a large number of samples would be required to demonstrate such correlations. Alternatively, these observations may support the possibility that alterations in FGF-8 and its receptors are mainly associated with early changes and development of PIN lesions of prostatic epithelium.

In conclusion, our results show that the components of the FGF-8 autocrine loop are expressed at an increased level in both premalignant PIN lesions and prostate cancer compared with normal-type epithelium. Additionally, the expression pattern of FGF-8 isoforms was clearly more heterogenous in prostate cancer than in control prostate specimens. These results suggest that FGF-8-mediated pathways are involved in the development of human prostate cancer.

\section{Methods}

\section{Tissue Samples}

The samples of prostate cancer were obtained from 31 patients (aged 47 to 74 years, mean 64 years) undergoing radical prostatectomy. The carcinomas were grouped according to their histologic grade (I, II, or III; World Health Organization [WHO] classification) (Mostofi, 1980) (well differentiated, moderately differentiated, or poorly differentiated) and according to their Gleason grade (Bostwick, 1994). Because of heterogenous distribution of cancer in prostates, histologic grade was confirmed from the area adjacent to the prostatic specimen from which the RNA sample was taken. Nonmalignant prostate tissues were obtained from 24 patients undergoing cystoprostatectomy because of bladder carcinoma (aged 43 to 77 years; mean 62 years). Although most of these prostates showed at least microscopic hyperplasia, they were thought to be representative of normal nonmalignant control prostate of elderly men, because the prevalence of benign prostatic hyperplasia in 61- to 70 -year-old men is $71 \% \pm 7.2 \%$ (Berry et al, 1984). Diagnostic criteria for PIN according to Bostwick (1995) were used. All of the samples studied were examined by an experienced pathologist (PM Martikainen). The Local Ethical Committee approved the collection and analysis of the prostate samples.

\section{RNA preparation and RT-PCR}

Total RNA was extracted by using the guanidinium isothiocyanate method of Chirgwin et al (1979) or 


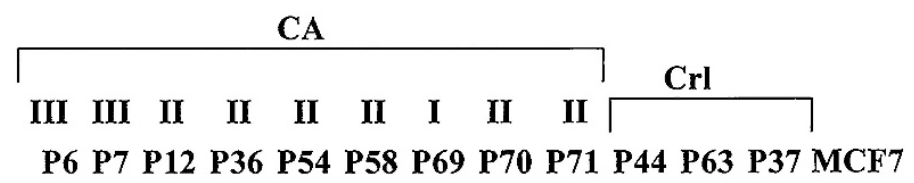

FGFR1IIIc

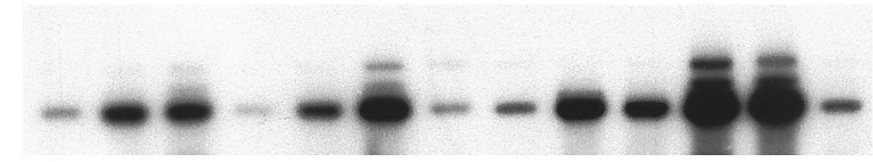

P6 P7 P12 P36 P54 P58 P69 P70 P71 P44 P63 P37 MCF7

\title{
FGFR2IIIb
}

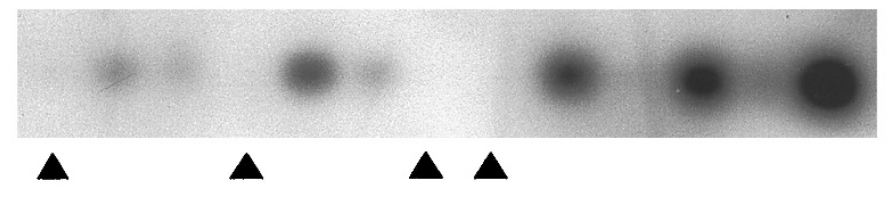

P6 P7 P12 P36 P54 P58 P69 P70 P71 P44 P63 P37 MCF7

\author{
FGFR2IIIc
}

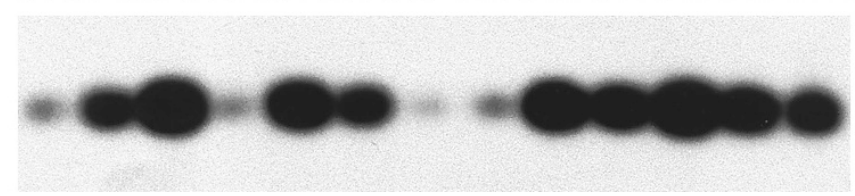

Figure 4.

Expression of FGF-8 receptors in control (Cr) and malignant $(C A)$ human prostate samples. Southern hybridization of FGF-8-receptor RT-PCR products using a specific oligonucleotide probe for FGFR1IIIc and FGFR2IIIb and a CDNA probe for FGFR2IIIc in prostate cancer, control prostate, and MCF7 cells (positive control). RT-PCR products from nine representative prostate cancer and three control specimens are shown. FGFR2IIIb RT-PCR reactions that were regarded as negative are marked with arrowheads.

Chomzynski and Sacchi (1987). Figure 6A shows the exon structure and splicing variants of the human FGF-8 gene according to Gemel et al (1996) and MacArthur et al (1995c). The primers used for FGF-8-isoform RT-PCR (arrows) were the same as reported in Ghosh et al (1996). The 5'-primer (RB416) 5'-TGAGCTGCCTGCTGTTGCACTT-3' is located in exons $1 \mathrm{~A}$ (begin) and 1B (end). The 3'-primer (RB418) 5'-TGAAGACGCAGTCCTTGCCTT-3' is located in the beginning of exon 3 . In Figure 6B, the arrow shows the second half of the third immunoglobulin-like loop, where splicing for the FGFR1, 2 , and 3 alternative forms (IIIb and IIlc) occurs. The specific primers used for this area of the FGFR1, 2, and 3 isoforms were as follows: for FGFR1Illc, 5'-primer 5'-TCTTCTGGGCTGTGCTG-3' and 3'-primer 5'CATCTCTITGTCGGTGGTATTAACTCCA-3', according to Ittman and Mansukhani (1997); for FGFR2Illb, 5'primer 5'-CACTCGGGGATAAATAGCTCCAAT-3' and 3'-primer 5'-CTTGCTGTTTGGGCAGGACAG-3'; and for FGFR2IIlc, 5'-primer 5'-GCCGCCGGTGTTAACACCACGGAC-3' and 3'-primer 5'-TGGCAGACCTGTCAACCATGCAGA-3', according to Miki et al (1992) and Savagner et al (1994). For FGFR3IIlc, a 5'-primer 5'ACCCTACGTTACCGTGCTCAA-3' and 3'-primer 5'CCGCCAGGCAGGTGTACT-3' for 30 cycles of $94^{\circ} \mathrm{C}, 1$ minute; $60^{\circ} \mathrm{C}, 1$ minute; $72^{\circ} \mathrm{C}, 3$ minutes. The FGFR4 primers were 5'-primer 5'-TCTGAGGAAGTGGAGCTTGA-3' and 3'-primer 5'-TAGTTATAGCGGATGCTGCC-3', according to Ittman and Mansukhani (1997). The sensitivity of the RT-PCR assay was examined by in vitro transcription of FGF-8a cDNA inserted into the pGEM3z vector. The FGF-8-isoform RT-PCR was performed from $0,10^{1}, 10^{2}, \ldots$ to $10^{10}$ copies of FGF-8a RNA. The FGF-8a PCR product was detectable from 10 copies of RNA (data not shown).

\section{Southern Blotting}

Samples $(20 \mu \mathrm{l})$ from the RT-PCR reaction mixtures for FGF-8 or FGFRs were run on $3 \%$ or $1 \%$ NuSieve 3:1 agarose gels (FMC BioProducts, Rockland, Maine), respectively, and transferred to the Gene Screen plus nylon membrane (DuPont NEN, Boston, Massachusetts) using standard conditions.

The specificity of the FGF-8 RT-PCR products was confirmed by Southern blots using an internal oligonucleotide probe (RB402) located at exon 1D, 5'TGAGCTGATCCGTCACCA-3', and common to all isoforms (Ghosh et al, 1996). The RT-PCR products for FGFR1IIlc and FGFR2IIlb were confirmed with the oligonucleotide probes 5'-TGTGTAAGGTGTACAGTGA-3' and 5'-GGATGCTGGGGAATATATA-3', respectively. The oligonucleotides were 3 '-end labeled with nonradioactive digoxigenin-11-ddUTP (DIGddUTP) (Boehringer Mannheim Biochemicals, Mannheim, Germany) according to the protocol of the manufacturer. Hybridization was carried out for 18 to 24 hours at $50^{\circ} \mathrm{C}$ for FGF-8, $48^{\circ} \mathrm{C}$ for FGFR1Illc, and $53^{\circ} \mathrm{C}$ for FGFR2IIIb. Washes and signal detection were as described in the DIG Luminescent detection protocol (Boehringer Mannheim Biochemicals), and the membranes were exposed to Konica Medical film 

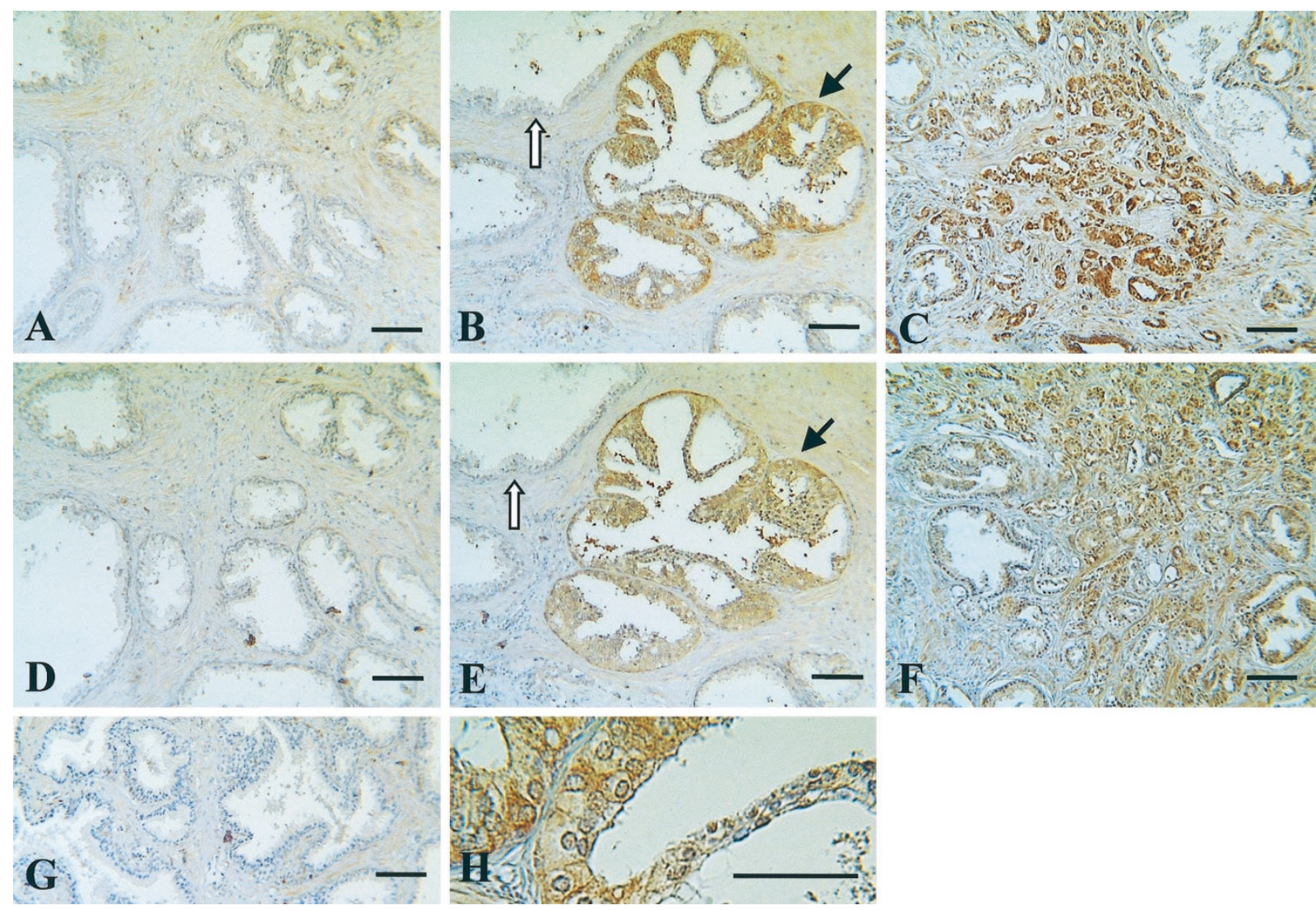

Figure 5.

Immunohistochemistry for FGFR1 and FGFR2 in control prostates and prostate cancer specimens, both containing PIN lesions. FGFR1 immunohistochemistry (A, B, $\mathrm{C}$, and $\mathrm{H}$ ) and FGFR2 immunohistochemistry (D, E, F) have stronger immunoreactivity in PIN lesions (black arrows in $\mathrm{B}$ and $\mathrm{E}$ ) and in cancer cells (C and F) than in normal epithelium (A, D, and white arrows in B and E). Localization of FGFR1 immunoreactivity to cell membranes and cytoplasm of control prostatic epithelium is shown in H. A control section (P26) with a normal rabbit serum substituted for the primary (G) was negative. (A to G: bar, $100 \mu \mathrm{m} ; \mathrm{H:} \mathrm{bar,} 50 \mu \mathrm{m}$ ).

(Konica Corporation, Tokyo, Japan) or Hyperfilm MP (Amersham Life Science, Little Chalfont, England) at room temperature for 15 to 30 minutes. The RT-PCR products of FGFR2Illc were confirmed by hybridization with $\left[{ }^{32} \mathrm{P}\right]-$ labeled FGFR2 (Dionne et al, 1990), using standard conditions.

\section{Sequencing}

To verify the Southern blot results, the FGF-8 and FGFR RT-PCR fragments were also sequenced by an ABI377 automatic sequencer (Applied Biosystems Perkin-Elmer, Foster City, California).

\section{Immunohistochemistry}

Serial sections $(5 \mu \mathrm{m})$ of paraffin-embedded prostate samples were cut and mounted on silane-coated glass slides. The sections were deparaffinized, rehydrated, and washed in PBS. The endogenous peroxidase activity was blocked by incubating the slides in $2 \%$ peroxide in PBS. Treatment in the microwave oven was used to unmask the antigen epitopes. After cooling the slides, the nonspecific binding of the $\operatorname{lgG}$ was minimized by a 30-minute preincubation of the slides in normal horse serum (Vector Laboratories, Inc., Burlingame, California) at room temperature. The primary polyclonal antibody to FGF-8, which recognizes all of the FGF-8 isoforms (N-19; Santa Cruz Biotechnology Inc., Santa Cruz, California) was applied overnight at a dilution of 1:100 in PBS at $+4^{\circ} \mathrm{C}$. Controls for specificity of FGF-8 immunoreactivity included incubation of randomly selected sections with normal goat IgG (R and D Systems, Minneapolis, Minnesota) at the same dilution as the primary antibody. The specificity of the FGF-8 antibody was demonstrated in our previous report (Valve et al, 2000). After washes in PBS, the samples were reacted with a biotinylated donkey anti-goat IgG secondary antibody (Jackson Immunoresearch, West Grove, Pennsylvania) at a 1:200 dilution for 30 minutes at room temperature. The detection was performed with an ABC kit (Vector Laboratories Inc.). The slides were reacted with diaminobenzidine, washed, counterstained with Mayer's hematoxylin, dehydrated, treated with xylene, and mounted.

The FGFR1 and FGFR2 immunohistochemistry was performed with primary rabbit antibodies to FGFR1 (C-15) and FGFR2 (C-17) (Santa Cruz Biotechnology Inc.), at a dilution of $3 \mu \mathrm{g} / \mathrm{ml}$ in PBS at $+4^{\circ} \mathrm{C}$ overnight. Controls for specificity of immunoreactivity included incubation of randomly selected sections with normal rabbit serum (Sigma Chemical Company, St. 
A.

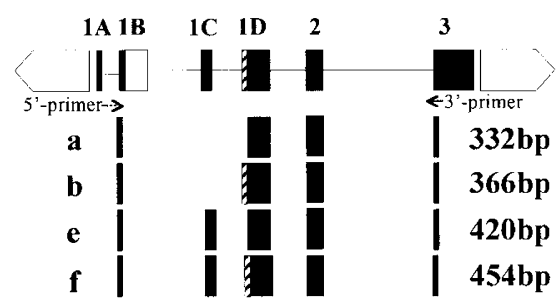

B.

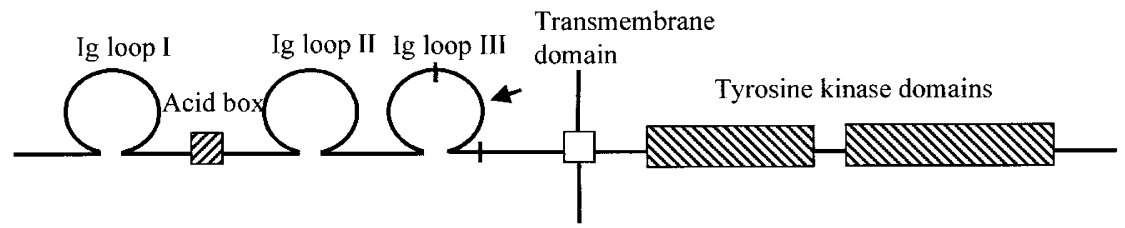

Figure 6.

A, The exon structure and splicing variants of the human FGF-8 gene (Gemel et al, 1996; MacArthur et al, 1995c). B, Structure of generalized FGFR. The positions of the RT-PCR primers used to amplify FGF-8 (arrows in A) and a region for alternative splicing of FGFR isoforms (arrow in B).

Louis, Missouri) in PBS. The specificity of these FGFR antibodies was previously demonstrated by Cancilla and Risbridger (1998). After washes in PBS, the samples were reacted with a biotinylated goat anti-rabbit IgG (Vector Laboratories Inc.) secondary antibody at a 1:200 dilution for 30 minutes at room temperature. The detection of the immunocomplexes was performed with an ABC kit (Vector Laboratories Inc.). The slides were reacted with diaminobenzidine, washed, counterstained with Mayer's hematoxylin, dehydrated, treated with xylene, and mounted.

The sections were independently analyzed by two investigators, and the intensities of FGF-8 and FGFR reactivities in various regions of the samples were estimated using the categories 0 (no reactivity), + (weak reactivity), ++ (moderate reactivity), and +++ (strong reactivity). The range of immunoreactivity from absent $(0)$ or weak $(+)$ to moderate $(++)$ or strong $(+++)$ reactivity in various parts of the sections was marked as $0 /+, 0 /++, 0 /+++,+/++,+/+++$, or $++/+++$, indicating heterogeneity within one sample (Tables 3 and 4).

\section{Statistical Analysis}

Differences between the expression of the FGF-8 isoforms a or e or FGF-8 isoform combinations in prostate cancer and control prostates were examined using the Fisher's exact test.

\section{Acknowledgements}

We thank Mrs. Anu Lillbacka, Mrs. Pirkko Rauhamäki, Mr. Jani Seppänen, and Mrs. Leena Simola for technical assistance. We also acknowledge the help of Dr. Markku Kallajoki in analyzing the clinical samples.

\section{References}

Berry SJ, Coffey DS, Walsh PC, and Ewing LL (1984). The development of human benign prostatic hyperplasia with age. J Urol 132:474-479.

Blunt AG, Lawshe A, Cunningham ML, Seto ML, Ornitz DM, and MacArthur CA (1997). Overlapping expression and redundant activation of mesenchymal fibroblast growth factor (FGF) receptors by alternatively spliced FGF-8 ligands. J Biol Chem 272:3733-3738.

Bostwick D (1995). High grade prostatic intraepithelial neoplasia: The most likely precursor of prostate cancer. Cancer 75:1823-1836.

Bostwick DG (1994). Grading prostate cancer. Am J Clin Pathol 102:S38-56.

Cancilla B and Risbridger GP (1998). Differential localization of fibroblast growth factor receptor-1, $-2,-3$, and -4 in fetal, immature, and adult rat testes. Biol Reprod 58:1138-1145.

Carstens RP, Eaton JV, Krigman HR, Walther PJ, and GarciaBlanco MA (1997). Alternative splicing of fibroblast growth factor receptor 2 (FGF-R2) in human prostate cancer. Oncogene 15:3059-3065.

Chevalier S, Aprikian A, Beauregard G, Defoy I, Nguyen L, Guenette R, Tenniswood M, and Chapdelaine A (1996). Action, localization and structure-function relationship of growth factors and their receptors in the prostate. Reprod Med Rev 5:73-105.

Chirgwin JM, Przybyla AE, MacDonald RJ, and Rutter WJ (1979). Isolation of biologically active ribonucleic acid from 
sources enriched in ribonuclease. Biochemistry 18:52945299.

Chomzynski P and Sacchi N (1987). Single-step method of RNA isolation by acid guanidium thiocyanate-phenolchloroform extraction. Anal Biochem 162:156-159.

Crossley PH and Martin G (1995). The mouse Fgf8 gene encodes a family of polypeptides and is expressed in regions that direct outgrowth and patterning in the developing embryo. Development 121:439-451.

Crossley PH, Martinez S, and Martin GR (1996a). Midbrain development induced by fgf 8 in the chick embryo. Nature 380:66-68.

Crossley PH, Minowada G, MacArthur CA, and Martin GR (1996b). Roles for FGF8 in the induction, initiation, and maintenance of chick limb development. Cell 84:127-136.

Dionne CA, Crumley G, Bellot F, Kaplow JM, Searfoss G, Ruta M, Burgess WH, Jaye M, and Schlessinger J (1990). Cloning and expression of two distinct high-affinity receptors cross-reacting with acidic and basic fibroblast growth factors. EMBO J 9:2685-2692.

Dorkin TJ, Robinson MC, Marsh C, Bjartell A, Neal DE, and Leung HY (1999). FGF8 over-expression in prostate cancer is associated with decreased patient survival and persists in androgen independent disease. Oncogene 18:2755-2761.

Gemel J, Gorry M, Ehrlich GD, and MacArthur CA (1996). Structure and sequence of human FGF8. Genomics 35:253257.

Ghosh AK, Shankar GM, Wu K, T'Ang A, Miller GJ, Zheng J, and Roy-Burman P (1996). Molecular cloning and characterization of human FGF8 alternative messenger RNA forms. Cell Growth Differ 7:1425-1434.

Giri D, Ropiquet F, and Ittmann M (1999). Alterations in expression of basic fibroblast growth factor (FGF) 2 and its receptor FGFR-1 in human prostate cancer. Clin Cancer Res 5:1063-1071.

Heikinheimo M, Lawshe A, Shackleford GM, Wilson DB, and MacArthur CA (1994). Fgf-8 expression in the postgastrulation mouse suggests roles in the development of the face, limbs and central nervous system. Mech Dev 48:129138.

Ittman M and Mansukhani A (1997). Expression of fibroblast growth factors (FGFs) and FGF receptors in human prostate. J Urol 157:351-356.

Johnson MR, Valentine C, Basilico C, and Mansukhani A (1998). FGF signaling activates STAT1 and p21 and inhibits the estrogen response and proliferation of MCF-7 cells. Oncogene 16:2647-2656.

Kouhara H, Koga M, Kasayama S, Tanaka A, Kishimoto T, and Sato B (1994). Transforming activity of a newly cloned androgen-induced growth factor. Oncogene 9:455-462.

Leung HY, Dickson C, Robson CN, and Neal DE (1996). Over-expression of fibroblast growth factor-8 in human prostate cancer. Oncogene 12:1833-1835.

Lorenzi MV, Long JE, Miki T, and Aaronson SA (1995). Expression cloning, developmental expression and chromosomal localization of fibroblast growth factor-8. Oncogene 10:2051-2055.

MacArthur CA, Lawshe A, Shankar DB, Heikinheimo M, and Shackleford GM (1995a). FGF-8 isoforms differ in NIH3T3 cell transforming potential. Cell Growth Differ 6:817-825.
MacArthur CA, Lawshe A, Xu JS, Santosocampo S, Heikinheimo M, Chellaiah AT, and Ornitz DM (1995b). FGF-8 isoforms activate receptor splice forms that are expressed in mesenchymal regions of mouse development. Development 121:3603-3613.

MacArthur CA, Shankar DB, and Shackleford GM (1995c). Fgf-8, activated by proviral insertion, cooperates with the Wnt-1 transgene in murine mammary tumorigenesis. J Virol 69:2501-2507.

Mahmood R, Bresnick J, Hornbruch A, Mahony C, Morton N, Colquhoun K, Martin P, Lumsden A, Dickson C, and Mason I (1995). A role for FGF-8 in the initiation and maintenance of vertebrate limb bud outgrowth. Curr Biol 5:797-806.

Marsh SK, Bansal GS, Zammit C, Barnard R, Coope R, Roberts-Clarke D, Gomm JJ, Coombes RC, and Johnston CL (1999). Increased expression of fibroblast growth factor 8 in human breast cancer. Oncogene 18:1053-1060.

Miki T, Bottaro DP, Fleming TP, Smith CL, Burgess WH, Chan AM, and Aaronson SA (1992). Determination of ligandbinding specificity by alternative splicing: Two distinct growth factor receptors encoded by a single gene. Proc Natl Acad Sci USA 89:246-250.

Mostofi FK (1980). Histological Typing of Prostate Tumours: International Histologic Classification of Tumours, no. 22. Geneva: World Health Organization.

Ohuchi H, Yoshioka H, Tanaka A, Kawakami Y, Nohno T, and Noji S (1994). Involvement of androgen-induced growth factor (FGF-8) gene in mouse embryogenesis and morphogenesis. Biochem Biophys Res Commun 204:882-888.

Ropiquet F, Giri D, Kwabi-Addo B, Mansukhani A, and Ittman M (2000). Increased expression of fibroblast growth factor 6 in human prostatic intraepithelial neoplasia and prostate cancer. Cancer Res 60:4245-4250.

Russell PJ, Bennett S, and Stricker P (1998). Growth factor involvement in progression of prostate cancer. Clin Chem 44:705-723.

Savagner P, Valles AM, Jouanneau J, Yamada KM, and Thiery JP (1994). Alternative splicing in fibroblast growth factor receptor 2 is associated with induced epithelialmesenchymal transition in rat bladder carcinoma cells. Mol Biol Cell 5:851-862.

Tanaka A, Furuya A, Yamasaki M, Hanai N, Kuriki K, Kamiakito $T$, Kobyashi $\mathrm{Y}$, Yoshida $\mathrm{H}$, Koike $\mathrm{M}$, and Fukayma $\mathrm{M}$ (1998). High frequency of fibroblast growth factor (FGF) 8 expression in clinical prostate cancers and breast tissues, immunohistochemically demonstrated by a newly established neutralizing antibody against FGF 8. Cancer Res 58:2053-2056.

Tanaka A, Miyamoto K, Minamino N, Takeda M, Sato B, Matsuo H, and Matsumoto K (1992). Cloning and characterization of an androgen-induced growth factor essential for the androgen-dependent growth of mouse mammary carcinoma cells. Proc Natl Acad Sci USA 89:8928-8932.

Valve E, Martikainen P, Seppänen J, Oksjoki S, Hinkka S, Anttila L, Grenman S, Klemi P, and Härkönen P (2000). Expression of FGF-8 isoforms and FGF-receptors in human ovarian tumors. Int J Cancer 88:718-725.

Valve E, Penttilä T-L, Paranko J, and Härkönen P (1997). FGF-8 is expressed during specific phases of rodent oocyte and spermatogonium development. Biochem Biophys Res Commun 232:173-177. 
Wang Q, Stamp GW, Powell S, Abel P, Laniado M, Mahony C, Lalani EN, and Waxman J (1999). Correlation between androgen receptor expression and FGF8 mRNA levels in patients with prostate cancer and benign prostatic hypertrophy. J Clin Pathol 52:29-34.

Yan G, Fukabori Y, McBride G, Nikolaropolous S, and McKeehan WL (1993). Exon switching and activation of stromal and embryonic fibroblast growth factor (FGF)-FGF receptor genes in prostate epithelial cells accompany stromal independence and malignancy. Mol Cell Biol 13:45134522.
Yan G, Fukabori Y, Nikolaropoulos S, Wang F, and McKeehan WL (1992). Heparin-binding keratinocyte growth factor is a candidate stromal-to-epithelial-cell andromedin. Mol Endocrinol 6:2123-2128. 